\title{
COMPARISON OF ORAL CLONIDINE WITH ORAL MIDAZOLAM IN MANAGING AGITATION FOLLOWING SEVOFLURANE ANESTHESIA: A PROSPECTIVE, RANDOMIZED, DOUBLE-BLINDED STUDY
}

\author{
ANTONY JOHN CHARLES $\mathbf{S}^{1}$, RAGHURAMAN MS ${ }^{1 *}$, RAJI SHARMA ${ }^{2}$, DAVID GEORGE VELIATH ${ }^{2}$ \\ ${ }^{1}$ Department of Anesthesiology, Mahatma Gandhi Medical College \& Research Institute, Puducherry, India, ${ }^{2}$ Department of Anesthesiology, \\ Pondicherry Institute of Medical Sciences, Puducherry, India. Email: drraghuram70@gmail.com
}

Received: 01 August 2016, Revised and Accepted: 06 August 2016

ABSTRACT

Objective: Emergence agitation is a major problem during recovery from anesthetic agents like sevoflurane, particularly in children. This study had compared the effects of oral clonidine with oral midazolam in reducing the incidence of emergence agitation following sevoflurane anesthesia.

Methods: A total of 50 children of ASA Status I and II aged between 3 and 8 years were randomly allotted to one of the two groups, each group comprising 25 children. Group I children were given oral midazolam $0.5 \mathrm{mg} / \mathrm{kg}$ and Group II children were given oral clonidine $4 \mathrm{mcg} / \mathrm{kg} 30 \mathrm{minutes}$ before the induction of anesthesia. The emergence reaction was analyzed using modified objective pain scale in all children following sevoflurane administration.

Results: The total agitation score was significantly less in clonidine group in comparison to midazolam group during the $1^{\text {st }} \mathrm{hr}$ of post-operative period $(\mathrm{p}<0.05)$. No remarkable change in the hemodynamics or oxygen saturation was observed in both groups.

Conclusion: Premedication of oral clonidine $4 \mathrm{mcg} / \mathrm{kg}$ is superior to oral midazolam $0.5 \mathrm{mg} / \mathrm{kg}$ in reducing the incidence of emergence agitation following sevoflurane anesthesia.

Keywords: Sevoflurane, Recovery, Emergence agitation, Clonidine, Midazolam.

(C) 2016 The Authors. Published by Innovare Academic Sciences Pvt Ltd. This is an open access article under the CC BY license (http://creativecommons. org/licenses/by/4. 0/) DOI: http://dx.doi.org/10.22159/ajpcr.2016.v9i6.14423

\section{INTRODUCTION}

Although sevoflurane has good properties like quicker induction and recovery, making it an ideal agent for children, it has some drawbacks of which emergence agitation is worth mentioning because it is common during recovery period [1]. Disorientation, hypersensitivity to stimuli and hyperactive motor behavior are the characteristics of this emergence reaction [1]. The exact cause for this reaction is not known. It is believed that pain is a contributing factor since analgesics reduce the incidence of this emergence reaction [2,3]. Restless recovery from anesthesia may not only cause injury to the child or to the surgical site but may also lead to accidental removal of surgical dressings, intravenous catheters, and drains. Additional nursing care may often be necessary as well as supplemental sedative and or analgesic medications, which may delay the discharge from the hospital. Clonidine, an alpha 2 agonist, has both sedative and analgesic effects [4,5]. Intravenous administration of clonidine, after induction of anesthesia reduces the incidence of emergence reactions following sevoflurane administration [6-8]. Tropisetron, the serotonin antagonist, used as an anti-emetic, also found to be useful in reducing the incidence of the emergence agitation following sevoflurane anesthesia [9]. Midazolam, which is a shortacting benzodiazepine, is commonly used as pre-medication to reduce pre-operative anxiety and for smooth induction of anesthesia. However, its efficacy in reducing the emergence reactions following sevoflurane anesthesia is questionable [10-12].

This study was done to assess the effect of oral midazolam in reducing the emergence reaction of sevoflurane in comparison to oral clonidine and also the effects of these two drugs on the hemodynamics and oxygen saturation during the perioperative period.

\section{METHODS}

After approval from the ethical committee of the institute, this study was conducted on 50 children, randomly divided into two groups of 25 each as per the inclusion/exclusion criteria to assess the efficacy of oral clonidine and oral midazolam in the prevention of sevoflurane-induced agitation in children during the post-operative period. The study was conducted in a medical college in south India from December 2008 to July 2010.

\section{Inclusion criteria}

A total of 50 children of ASA Status I and II aged between 3 and 8 years who were undergoing circumcision, tonsillectomy, adenoidectomy, myringotomy and herniotomy.

\section{Exclusion criteria}

1. Patients of ASA Status III and IV

2. Family history of malignant hyperthermia, mental retardation, and a history of agitation or any other neurological disease, potentially associated with symptoms of agitation.

After approval from the Institute Ethical Committee, this study was conducted on 50 children as per the inclusion/exclusion criteria. After obtaining the written informed consent from the parent, the children were randomly allotted into one group - Group I or II, by block randomization method.

After a fasting period of $6 \mathrm{hrs}$, Group I children were given oral midazolam $0.5 \mathrm{mg} / \mathrm{kg}$ and Group II children were given oral clonidine $4 \mathrm{mcg} / \mathrm{kg}$ 30 minutes before the induction of anesthesia. This premedication was mixed with $3 \mathrm{ml}$ of sugar syrup/juice. Anesthesiologist involved in the study was blinded to the premedication.

After connecting the monitors (electrocardiogram, non-invasive blood pressure and pulse oximeter), anesthesia was induced by a single breath induction method using sevoflurane (8\%) in a 50:50\% mixture of nitrous oxide and oxygen with a fresh gas flow of $6 \mathrm{~L} /$ minute. For children weighing $\leq 20 \mathrm{~kg}$, Jackson-Rees circuit was used, whereas in 
children weighing $\geq 20 \mathrm{~kg}$, circle system was used. After achieving adequate depth of anesthesia (Guedel phase 3), the inspired sevoflurane concentration was reduced to $4 \%$.

After securing intravenous cannulation, injection glycopyrrolate $10 \mathrm{mcg} / \mathrm{kg}$ was given intravenously. Injection succinylcholine $2 \mathrm{mg} / \mathrm{kg}$ was given to facilitate endotracheal intubation with appropriate size. Injection fentanyl $2 \mathrm{mcg} / \mathrm{kg}$ was given before incision and inspired sevoflurane concentration was adjusted to $1.5 \%$. All the children were given paracetamol $30 \mathrm{mg} / \mathrm{kg}$ body weight in suppository form at this point.

At the beginning of skin closure, sevoflurane concentration was reduced to $0.7 \%$ and was stopped at the time of last suture, while maintaining a 50:50\% mixture of nitrous oxide and oxygen until the end of the wound dressing. Systolic and diastolic blood pressure, heart rate and oxygen saturation were measured every 5 minutes throughout the procedure. The child was allowed to breathe $100 \% \mathrm{O}_{2}$ until complete recovery of reflexes.

Systolic and diastolic blood pressure, heart rate and oxygen saturation were measured every 10 minutes for a period of $2 \mathrm{hrs}$ in the postoperative period. In addition, all the children were evaluated for the state of agitation as per the modified objective pain scale [13], every 15 minutes in the recovery room during the $1^{\text {st }} \mathrm{hr}$ after surgery, in the presence of one of the parents. The full objective pain scale included five criteria, namely, the blood pressure, crying, agitation, behavior, verbal or body expressions whereas the modified objective pain scale constituted only three $[14,15]$. Tears (crying), movements (agitation), behavior were those three criteria used in the modified scale. Each criterion has scores from 0 to 2 , so the maximum score possible is six. Total score of three or more is considered as agitation (Table 1).

\section{Statistical analysis}

Proportion, mean and standard deviation were used as descriptive statistics. Independent $t$-test was used for inferential statistics. All analyses were carried out using EPI INFO 6 version.

\section{RESULTS}

A total of 50 patients were recruited for this study of these 27 males and 23 females. The gender distribution was 12 males and 13 females in Group I and 15 males and 10 females in the Group II. The mean values for age and weight did not differ significantly between groups.

Table 1: The modified objective pain scale

\begin{tabular}{ll}
\hline Score & \\
\hline Tears & 0 \\
Absent & 1 \\
Present, but child can be consoled & 2 \\
Present and child cannot be consoled & \\
Movements & 0 \\
Absent & 1 \\
Moderate agitation (does not sit still) & 2 \\
Intense agitation (risk of trauma) & 0 \\
Behavior & 1 \\
Sleeping or calm & 2 \\
Grimacing, trembling voice, can be calmed down & \\
Frightened, sticks to parents, cannot be calmed down & \\
\hline
\end{tabular}

The pre-operative hemodynamic parameters heart rate, systolic blood pressure, diastolic blood pressure, and oxygen saturation did not differ significantly between groups.

There were no remarkable events like severe tachycardia or bradycardia, hypotension or hypertension, fall in saturation observed in both the groups.

The total agitation score was significantly less in clonidine group in comparison to midazolam group during the $1^{\text {st }} \mathrm{hr}$ of post-operative period (Table 2).

\section{DISCUSSION}

This was a prospective, randomized, double-blinded, comparative study. Our study has demonstrated that oral clonidine at a dose of $4 \mathrm{mcg} / \mathrm{kg}$ is more effective than oral midazolam of $0.5 \mathrm{mg} / \mathrm{kg}$ in preventing the post-operative agitation following sevoflurane anesthesia. Tazeroualti et al. had done a study on 68 children to compare the effects of oral clonidine with oral midazolam in preventing the sevoflurane-induced agitation [15]. They found that the modified objective pain score was significantly lower in the clonidine $4 \mathrm{mcg} / \mathrm{kg}$ group (median score 3 ) when compared to clonidine $2 \mathrm{mcg} / \mathrm{kg}$ (median score 5.5) or midazolam $0.5 \mathrm{mg} / \mathrm{kg}$ (median score 6.5) groups. They had also observed that the proportion of children with agitation in the $1^{\text {st }} \mathrm{hr}$ of recovery was significantly lower in the clonidine $4 \mathrm{mcg} / \mathrm{kg}$ group compared with midazolam group. The results of our study fairly correlate with that of Tazeroualti et al. [15]. We had not studied the prolonged agitation unlike them. They found that the proportion of children with prolonged agitation (agitation lasting for more than 15 minutes) was also significantly lower in the clonidine $4 \mathrm{mcg} / \mathrm{kg}$ group.

Bergendahl et al. had compared the effects of midazolam $0.3 \mathrm{mg}$ per $\mathrm{kg}$ with clonidine $5 \mathrm{mcg} / \mathrm{kg}$ administered rectally as premedication [16]. They observed that clonidine group had significantly lower objective pain scale score. Our results also correlate with them although the route of administration was different. Almenrader et al. had done a study comparing the effects of oral midazolam $0.5 \mathrm{mg} / \mathrm{kg}$ with oral clonidine $4 \mathrm{mcg} / \mathrm{kg}$ in children [17]. They observed that clonidine was superior in acceptance, anxiolysis, recovery profile and parental satisfaction although the anesthetic agent was not specific like in our study which was sevoflurane. Kulka et al. also observed that clonidine significantly reduces the incidence and severity of post-operative agitation in children after sevoflurane anesthesia and also safe [6]. However, they had used clonidine intravenously $2 \mathrm{mcg} / \mathrm{kg}$ and also after the induction of anesthesia.

Lankinen et al. had done a study comparing the effects of intravenous clonidine $1.5 \mathrm{mcg} / \mathrm{kg}$ and tropisetron $0.1 \mathrm{mg} / \mathrm{kg}$ and found that tropisetron was more effective in reducing the incidence of emergence agitation after sevoflurane anesthesia [9]. We think that it could be due to the dosage of clonidine because intravenous clonidine $2 \mathrm{mcg} / \mathrm{kg}$ was effective according to Kulka et al., Tesoro et al. and Malviya et al., although it was compared with placebo [6-8].

Thus, we believe that oral clonidine is better than oral midazolam in preventing the emergence reaction following sevoflurane anesthesia. This is noteworthy because the incidence of emergence reaction following sevoflurane administration is significant [18]. Indeed, the

Table 2: Comparison of modified objective pain scores of patients given midazolam and clonidine

\begin{tabular}{|c|c|c|c|c|c|c|c|}
\hline \multirow[t]{2}{*}{ Time } & \multicolumn{2}{|c|}{ Total agitation score with midazolam } & \multicolumn{2}{|c|}{ Total agitation score with clonidine } & \multirow[t]{2}{*}{$\mathbf{p}$} & \multirow[t]{2}{*}{$\mathbf{t}$} & \multirow[t]{2}{*}{ dz } \\
\hline & n (\%) & Mean \pm SD & n (\%) & Mean \pm SD & & & \\
\hline 15 minutes & $25(100)$ & $3.96 \pm 1.21$ & $25(100)$ & $1.92 \pm 0.76$ & 0.0001 & 7.14 & 48 \\
\hline 30 minutes & $25(100)$ & $3.16 \pm 0.85$ & 25 (100) & $1.40 \pm 0.82$ & 0.0001 & 7.54 & 48 \\
\hline 45 minutes & $25(100)$ & $2.72 \pm 0.94$ & $25(100)$ & $1.08 \pm 0.86$ & 0.0001 & 6.45 & 48 \\
\hline 60 minutes & $25(100)$ & $2.28 \pm 0.94$ & 25 (100) & $0.80 \pm 0.82$ & 0.0001 & 5.90 & 48 \\
\hline
\end{tabular}


incidence of emergence delirium is more with sevoflurane than with desflurane administration, although desflurane produces quicker recovery [19].

The limitation of our study is that we did not evaluate the mask acceptance, anxiolysis and parental satisfaction.

\section{CONCLUSION}

We conclude that premedication of oral clonidine $4 \mathrm{mcg} / \mathrm{kg}$ is superior to oral midazolam $0.5 \mathrm{mg} / \mathrm{kg}$ in reducing the incidence of emergence agitation following sevoflurane anesthesia.

\section{ACKNOWLEDGMENT}

We sincerely thank Mr. G. Ezhumalai, Msc. PhD, Senior statistician and Research consultant of Sri Balaji Vidyapeeth University, Puducherry, India, for guiding us in statistics.

\section{REFERENCES}

1. Constant I, Seeman R. Inhalational anesthetics in pediatric anesthesia. Curr Opin Anaesthesiol 2005;18(3):277-81.

2. Cravero JP, Beach M, Thyr B, Whalen K. The effect of small dose fentanyl on the emergence characteristics of pediatric patients after sevoflurane anesthesia without surgery. Anesth Analg 2003;97(2):364-7.

3. Davis PJ, Greenberg JA, Gendelman M, Fertal K. Recovery characteristics of sevoflurane and halothane in preschool-aged children undergoing bilateral myringotomy and pressure equalization tube insertaion. Anesth Analg1999;88(1):34-8.

4. Nishina K, Mikawa K. Clonidine in paediatric anaesthesia. Curr Opin Anaesthesiol 2002;15(3):309-16.

5. Bergendahl H, Lönnqvist PA, Eksborg S. Clonidine: An alternative to benzodiazepines for premedication in children. Curr Opin Anaesthesiol 2005;18(6):608-13.

6. Kulka PJ, Bressem M, Tryba M. Clonidine prevents sevofluraneinduced agitation in children. Anesth Analg 2001;93(2):335-8.

7. Tesoro S, Mezzetti D, Marchesini L, Peduto VA. Clonidine treatment for agitation in children after sevoflurane anesthesia. Anesth Analg 2005;101(6):1619-22.

8. Malviya S, Voepel-Lewis T, Ramamurthi RJ, Burke C, Tait AR. Clonidine for the prevention of emergence agitation in young children: Efficacy and recovery profile. Paediatr Anaesth 2006;16(5):554-9.

9. Lankinen U, Avela R, Tarkkila P. The prevention of emergence agitation with tropisetron or clonidine after sevoflurane anesthesia in small children undergoing adenoidectomy. Anesth Analg 2006;102(5):1383-6.

10. Voepel-Lewis T, Malviya S, Tait AR. A prospective cohort study of emergence agitation in the pediatric postanesthesia care unit. Anesth Analg 2003;96(6):1625-30.

11. McGraw $T$, Kendrick A. Oral midazolam premedication and postoperative behaviour in children. Paediatr Anaesth 1998;8(2):117-21.

12. Breschan C,Platzer M,Jost R,Stettner H,Likar R.Midazolam does no reduce emergence delirium after sevoflurane anesthesia in children. Pediatric Anesthesia Volume 17(4):347-52.

13. Joly A, Ecoffey C. Postoperative pain. Particularities in the child of less than 5 years, neonatology excluded. Ann Fr Anesth Reanim 1998;17(6):633-41.

14. Bock M, Kunz P, Schreckenberger R, Graf BM, Martin E, Motsch J Comparison of caudal and intravenous clonidine in the prevention of agitation after sevoflurane in children. Br J Anaesth 2002;88(6):790-6.

15. Tazeroualti N, De Groote F, De Hert S, De Villé A, Dierick A, Van der Linden P. Oral clonidine vs midazolam in the prevention of sevoflurane-induced agitation in children. A prospective, randomized, controlled trial. Br J Anaesth 2007;98(5):667-71.

16. Bergendahl HT, Lönnqvist PA, Eksborg S, Ruthström E, Nordenberg L, Zetterqvist $\mathrm{H}$, et al. Clonidine vs. Midazolam as premedication in children undergoing adeno-tonsillectomy: A prospective, randomized controlled clinical trial. Acta Anaesthesiol Scand 2004;48:1292-300.

17. Almenrader N, Passariello M, Coccetti B, Haiberger R, Pietropaoli P. Premedication in children: A comparison of oral midazolam and oral clonidine. Paediatr Anaesth 2007;17:1143-9.

18. Aono J, Ueda W, Mamiya K, Takimoto E, Manabe M. Greater incidence of delirium during recovery from sevoflurane anesthesia in preschool boys. Anesthesiology 1997;87:1298-300.

19. He J, Zhang Y, Xue R, Lv J, Ding X, Zhang Z. Effect of desflurane versus sevoflurane in pediatric anesthesia: A meta-analysis. J Pharm Pharm Sci 2015;18:199-206. 